\title{
Design of dual-mode SIR bandpass filter based on shorting pin for wireless communication applications
}

\author{
Jenan Ayad, Mustafa A. Jalil \\ Al-Esraa University College, Iraq
}

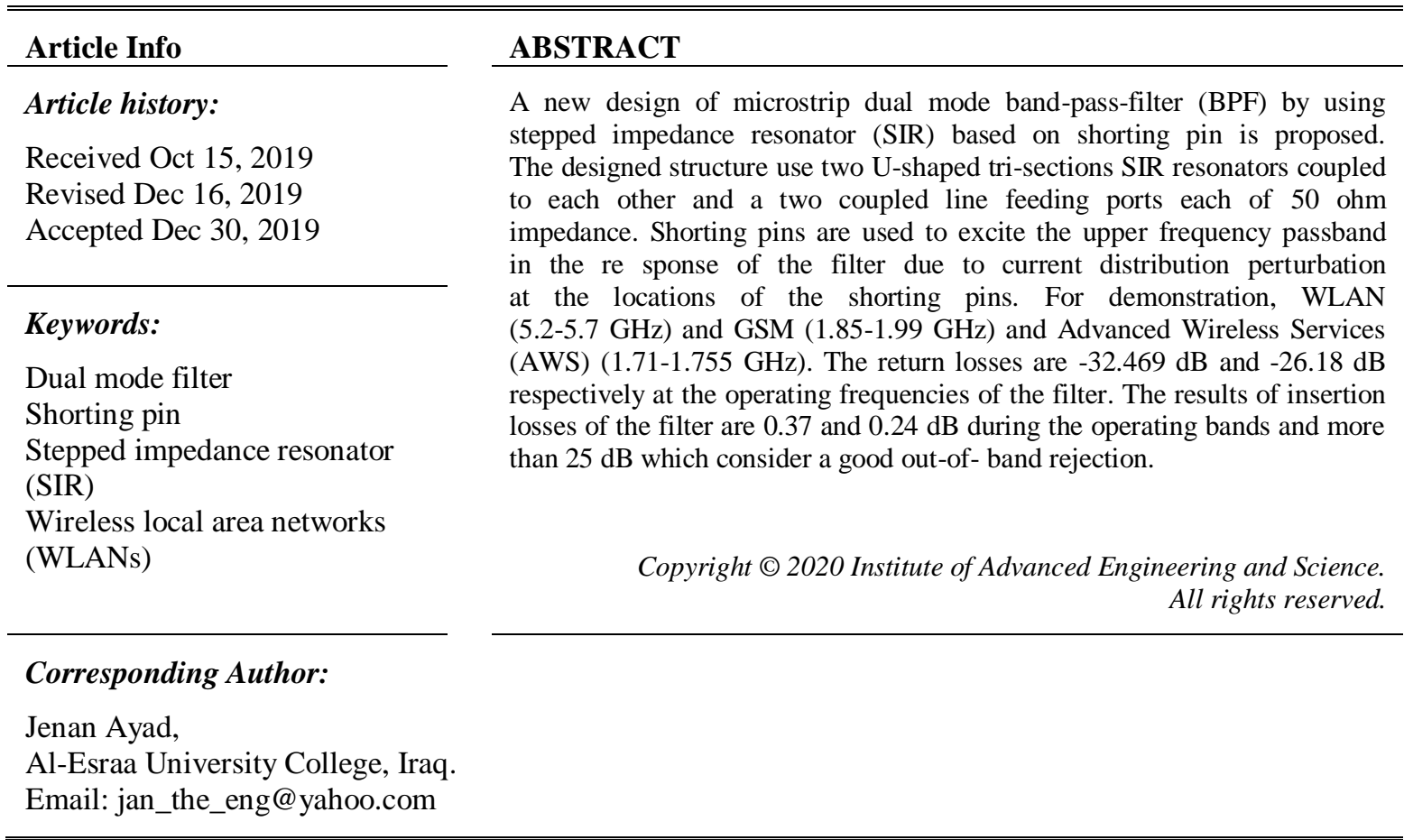

\section{INTRODUCTION}

Presently, wireless communication systems like wireless code division multiple access (WCDMA), mobile communication systems (GSM, CDMA, WCDMA, TD-SCDMA), and especially IEEE standards for wireless networks such as WLANs IEEE 802.11g and IEEE 802.11b that operate at $2.4 \mathrm{GHz}$ frequency; and products of IEEE 802.11 a operate at $5.8 \mathrm{GHz}$ frequency $[1,2]$, the communication systems with short range such as UWB and Bluetooth, which provide suitable communication services in modernistic society. The compact equipment which support multimode wireless systems are attractive and will be openly applied in the future [3, 4]. Besides simple designed realization, low pass-band insertion loss, high selectivity, the requisite requirement of band-pass filters for wireless communication systems is large stopband characteristics and a consolidated size this is substantial in new generation of wireless communication systems. Band-pass-filter (BPF) has a substantial role in the communication systems devices. BPF can be designed as a multi-mode circuit [5].

Dual mode resonators have very desirable features for design of band-pass filter (BPF), like low radiation loss, size miniaturization, and ease designing due to transmission line theory. The dual mode microstrip filters are significant in minimization techniques due to the high performance, they can be implemented as a double circuit in one structure with compared to designs of single mode band-pass filter when two decadent modes are coupled to each other by appropriate disturbance stimulation [6-8]. A dual mode resonator can be used as a double tuned circuit [9]. Thus, the number of resonators desired is reduced to half for a given degree of filter, which leads to a compact filter setup [10, 11].

Stepped impedance resonators (SIR) may be defined as a TEM or quasi-TEM mode resonators consist of multiple transmission lines with different characteristic impedance [12]. SIR filters are designed as several line sections of non-uniform widths coupled together with common input-output [5]. The second 
pass-band in the frequency response of dual-mode resonator is really a harmonic response, and it can be set by the structural parameters of the SIR [10]. Filter may require a huge circuit area or footprint, when it designed at a low microwave frequency. To eliminate this problem and for getting best utilization a multi-layer circuit technique, a new connotation of folded resonator, can be applied for minimizing filters $[12,13]$. Moreover, the dual mode microstrip resonators in the microwave printed are supplied by a pair of orthogonal feed lines organized in $90^{\circ}$ (or $270^{\circ}$ ) in order to get the two decadent modes and pairing them to each other. However, the orthogonal feed lines may not be physically appropriate for all microwave networks. Dual-mode microstrip filters may be fed by a pair of feed lines adjusted at $180^{\circ}$ geometrically, over a straight line $[14,15]$.

In this paper, a dual mode band-pass filter is proposed by using two U-shaped tri-sections SIR resonators paired with each other and a two coupled line feeding ports each with impedance of 50 ohms. In the response of the filter, shorting pins are used for excitation the upper frequency pass-band due to current distribution perturbation at the locations of the shorting pins for WLAN applications. The structure and dimensions of the filter are implemented and optimized by using commercial electromagnetic simulator CST microwave studio.

\section{DUAL-MODE STEPPED IMPEDANCE RESONATOR (SIR)}

The fundamental design of half wavelength SIR contains two lines of various characteristic impedances which are $Z_{1}$ and $Z_{2}$ with electrical lengths $\theta_{1}$ and $\theta_{2}$ as shown in Figure 1(a). It structured by cascading a long length $\left(2 \theta_{1}\right)$ at low impedance section $\left(Z_{1}\right)$ in the center and in the two sides end contacted with the short length $\left(\theta_{2}\right)$ at high impedance section $\left(Z_{2}\right)$ [16]. Utilizing a folded stepped impedance resonator, source load (input/output) coupling can easily be applied to produce transmission zeros in the stopband as indicated in Figure 1(b) [16, 17].

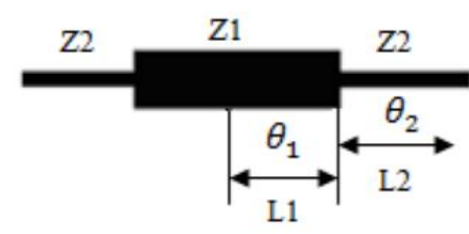

(a)

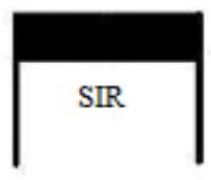

(b)

Figure 1. Dimensional and Electrical parameters of a resonator, (a) stepped impedance resonator (SIR),

(b) folded SIR structure

The conditions of resonance can be gained from one of them since the half-wavelength SIR is symmetrical [18]. The resonator impedance can be computed as the following form [15]:

$$
Z_{\text {in }}=j Z_{2} \frac{Z_{1} \tan \theta_{1}+Z_{2} \tan \theta_{2}}{Z_{1}-Z_{2} \tan \theta_{1} \tan \theta_{2}}
$$

According to (1), the resonance occurs when $Z_{\text {in }}$ is infinite, specifically the denominator of (1) is equal to zero. Therefore, the following form can be obtained as the resonance condition [19]:

$$
\frac{z_{2}}{z_{1}}=\tan \theta_{1} \tan \theta_{2}=R_{z}
$$

where $R_{z}$ is the impedance ratio. The resonance conditions are determined by $\theta_{1}, \theta_{2}$ and $R_{z}$ as given in (2). These three factors are required to generate the resonance that, and a dual mode filter can be designed by using SIR $[19,20]$.

The $\theta_{1}$ is equal to the $\theta_{2}$ in most practical application. In this case, the first spurious resonance appears at

$$
\tan \theta_{s 1}=\infty
$$

where $\theta_{s 1}$ is the electrical length for the first spurious frequency $f_{s 1}$. 
The ratio $U$ of the electrical length $[16,21]$.

$$
U=\theta_{2}\left(\theta_{1}+\theta_{2}\right)
$$

The electrical lengths differ from the physical lengths due to the effective dielectric constants are different for the two lines.

$$
\theta=\beta l
$$

where $l$ is the physical length of the microstrip. Thus, $\theta=\pi$ when $l=\frac{\lambda_{g}}{2}$ in this case, the physical length is called a half wavelength microstrip line that is used in this design [19]. From (2) by changing the value of $R_{z}$ and the lengths of the high- $Z$ and low- $Z$ segments, the resonant frequencies of an SIR are tuned [22].

Shorting pins are used to reduce the size without change the value of the substrate material permittivity [23]. The shorting pin is applied to the resonant circuit results with length equal to the substrate depth to satisfy short circuit with ground, effectively coupled to the lower degenerate mode and reduces the lower edge band resonant frequency [24]. By adjusting the resonator dimensions and the size of the shorting pin, the resonant frequency and the out-of band rejection around the transmission bands could be controlled to meet the design requirements.

The shorting pin can be represented as short circuit with inductor element in Figure (2).
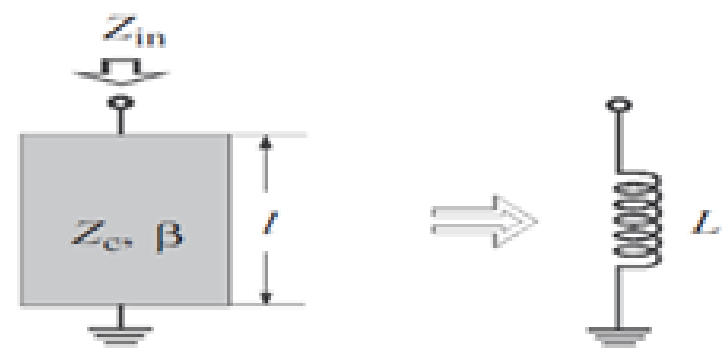

Figure 2. Equivalent circuit of short-circuited stub

Such a short section is similar to the short-circuited stub functions; therefore, it can be represented as a shunt lumped-element inductance given by [25]:

$$
L=\frac{Z_{c} l}{v_{p}}
$$

where $\mathrm{vp}$ is the phase velocity, $\mathrm{Zc}$ is characteristic impedance and 1 is the length of shorting pin.

\section{DESIGN AND CONFIGURATION OF DUAL-MODE STEPPED IMPEDANCE BPF}

The structure of microstrip BPF is composed of two U-shaped tri-sections SIR resonators coupled to each other and two coupled line feeding ports to $50 \Omega$ input-output capacitive coupling feeding lines as shown in Figure 3. Figure 3 shows the layout of the resulting filter. The filter designed on substrate dimensions of $7.05 \times 4.9 \mathrm{~mm} 2$ with a relative dielectric constant of equal 10.8 and scaling thickness equal $0.747 \mathrm{~mm}$. The proposed filter is fed by two $50 \mathrm{Ohm}$ microstrip lines of width $1 \mathrm{~mm}$, and they are symmetrically located at both ports.

The dimensions of this dual band filter are given as shown in Figure 3 and the radius of shorting pin represented by (r) and its depth equal to substrate thickness, where all dimension given in mm. Each SIR has capacitive coupling due to the capacitive reactance of the input and output feed lines, which is equivalent to an LC resonant circuit as shown in Figure 4 [25]. The values of L, C and the capacitances represent the gap are calculated by microstrip equations on and gives these values $\mathrm{L}=0.385 \mathrm{nH}, \mathrm{C}=0.146 \mathrm{pF}, \mathrm{Cp}=0.0077 \mathrm{pF}, \mathrm{Cg}=$ $0.132 \mathrm{pF}$ 


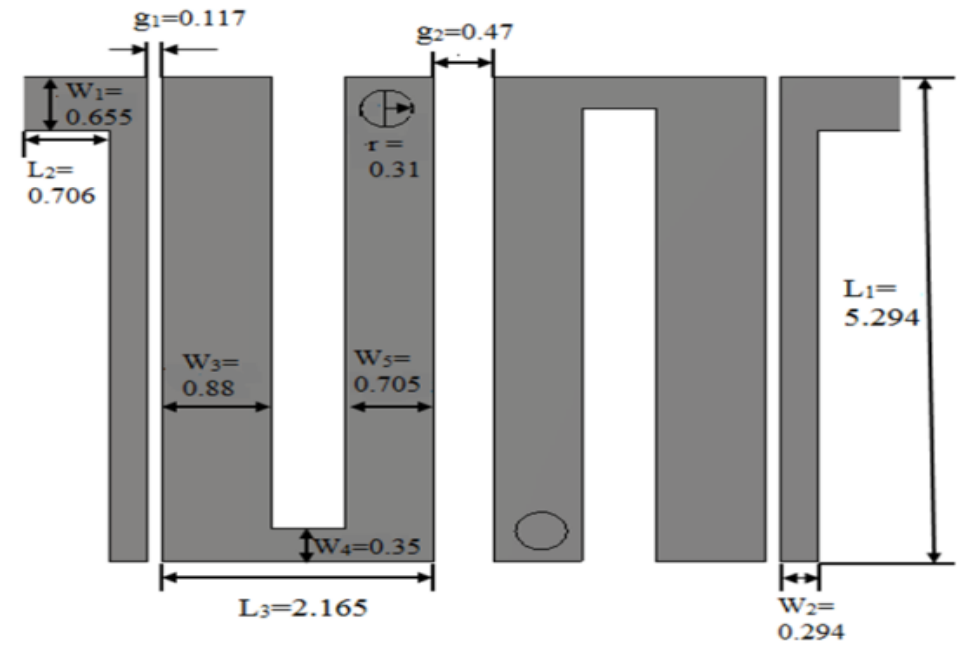

Figure 3. The proposed printed BP with its parameter

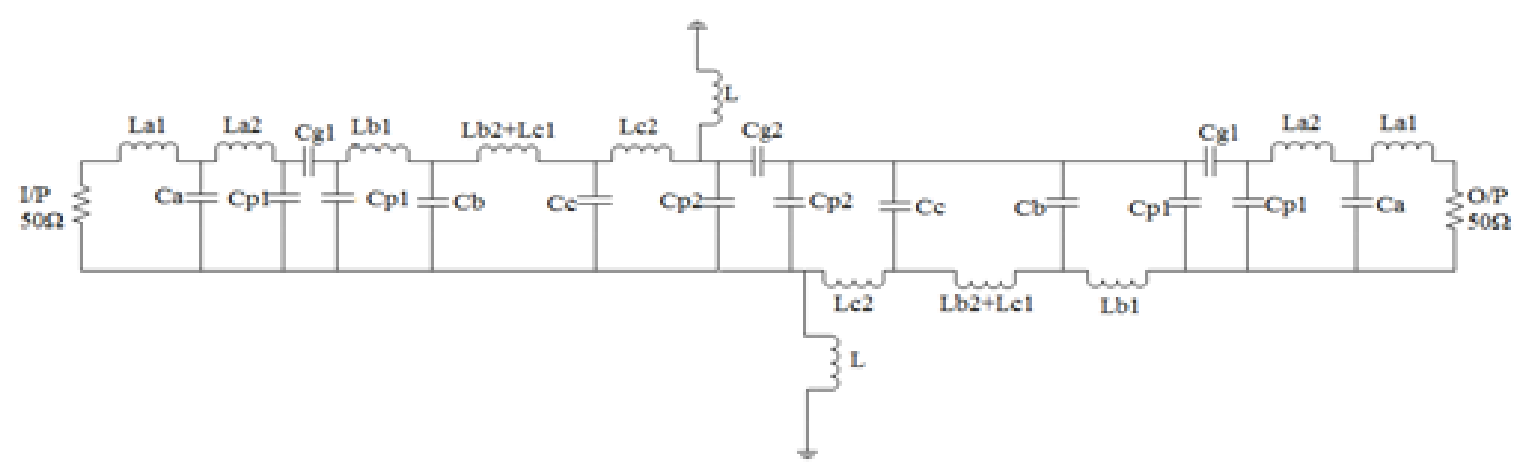

Figure 4. Equivalent circuit of proposed filter

\section{RESULTS}

The frequency response obtained of the proposed band-pass filter is illustrated in Figure 5. Two bands with dual-mode are clearly observe. And shows that the center frequencies of the lower and upper bands are $2.53 \mathrm{GHz}$ and $7.269 \mathrm{GHz}$ respectively. The lower band is very useful for WLAN applications. The return and insertion loss represent the frequency response results can be summarized in Table 1.

Table 1. Details of the Proposed Filter Frequency Response of Figure 5

\begin{tabular}{|c|c|c|}
\hline Parameters & $1^{\text {st }}$ band & $2^{\text {nd }}$ band \\
\hline FBW\% & $12.4 \%$ & $8.8 \%$ \\
\hline $\mathrm{S}_{11}$ & $\begin{array}{l}-15.858 \mathrm{~dB} \text { at } 2.377 \mathrm{GHz} \\
-17.43 \mathrm{~dB} \text { at } 2.692 \mathrm{GHz}\end{array}$ & $\begin{array}{l}-15.15 \mathrm{~dB} \text { at } 6.949 \mathrm{GHz} \\
-14.112 \mathrm{~dB} \text { at } 7.589 \mathrm{GHz}\end{array}$ \\
\hline Center Frequency & $2.53 \mathrm{GHz}$ & $7.269 \mathrm{GHz}$ \\
\hline Minimum IL & $\begin{array}{l}-0.344 \mathrm{~dB} \text { at } 2.377 \mathrm{GHz} \\
-0.256 \mathrm{~dB} \text { at } 2.692 \mathrm{GHz}\end{array}$ & $\begin{array}{l}-2.94 \mathrm{~dB} \text { at } 6.949 \mathrm{GHz} \\
-1.536 \mathrm{~dB} \text { at } 7.589 \mathrm{GHz}\end{array}$ \\
\hline $\begin{array}{c}\text { Transmission } \\
\text { Zeros }\end{array}$ & $-83.187 \mathrm{~dB}$ at $0.1 \mathrm{GHz}$ & $-49.566 \mathrm{~dB}$ at $4.962 \mathrm{GHz}$ \\
\hline
\end{tabular}


The surface current distributions of the proposed miniaturized filter at resonance frequencies of the lower and upper bands are shown in Figure 6. It has been clearly depicted that the currents are concentrates at the bends of the resonators along the regions contains shorting pins. In Figure 6(c) and (d), it can be seen that the gap between feeder line and resonator as well as the length of the resonator section contains shorting pin have direct effects on filter response at the upper band resonance frequencies 6.949 and $7.589 \mathrm{GHz}$ respectively.

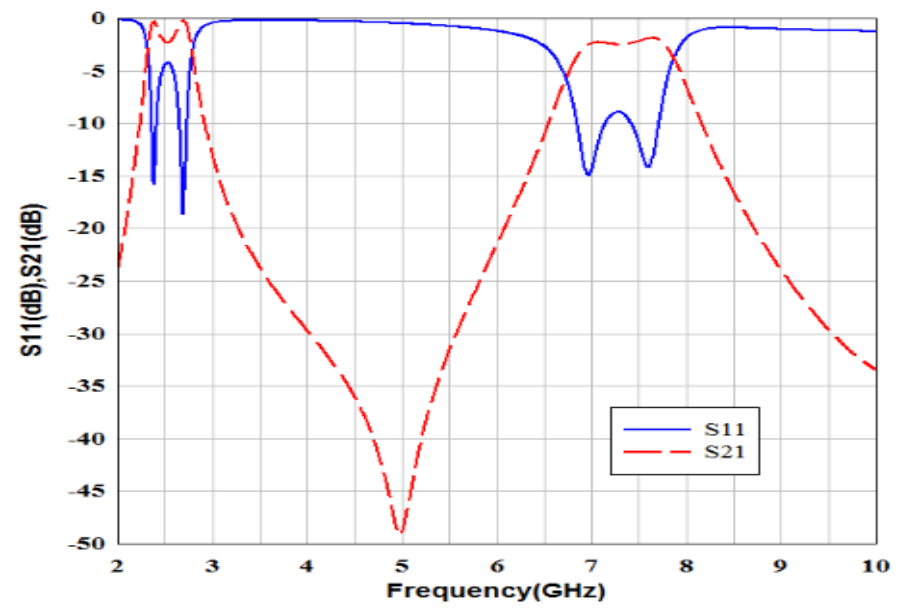

Figure 5. Return loss and insertion loss
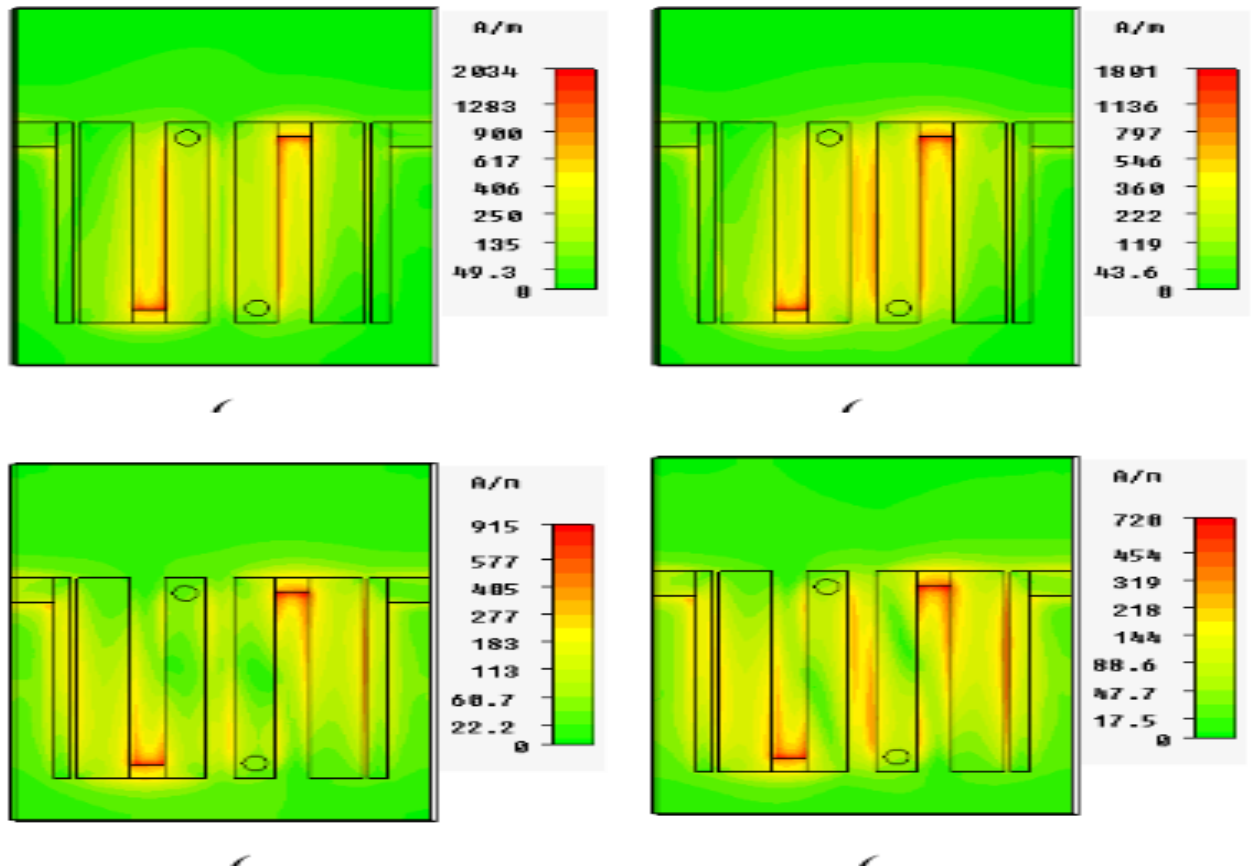

Figure 6. Surface current distribution $(a) f_{1}=2.377 \mathrm{GHz},(b) \mathrm{f}_{2}=2.692 \mathrm{GHz},(\mathrm{c}) \mathrm{f}_{3}=6.949 \mathrm{GHz},(\mathrm{d}) \mathrm{f}_{4}=7.589 \mathrm{GHz}$

Figure 6 simplify imposed modification regions. As shown in Figure 6 the large amount of current is concentrated along the resonators. Therefore, increasing the dimensions of the resonator will increase the path of the current which leads to decreasing the center frequencies of the resonant bands towards useful frequencies for wireless communication applications. The resulting filter designed and simulated on substrate size $10.4 \times 7.05 \mathrm{~mm} 2$. The length of resonators (L1) and width of bend (W4) are increased to be (7.694, 0.6) mm, respectively, see Figure 7.

Figure 8 shows the return and insertion losses of the modified filter structure. Modification effect benefits have been achieved through the enhancement of the frequency response performance. The new 
position of the bands is covered the wireless applications. Another band with center frequency of about 9.5 GHz is degenerated and can be used in another application. Performance response parameters of Figure 8 are listed on Table 2.

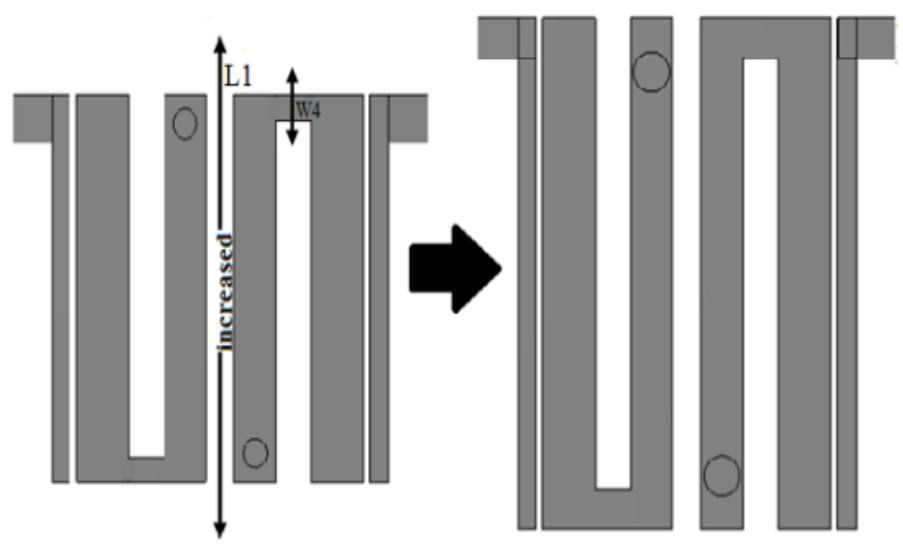

Figure 7. Scaling filter and its length

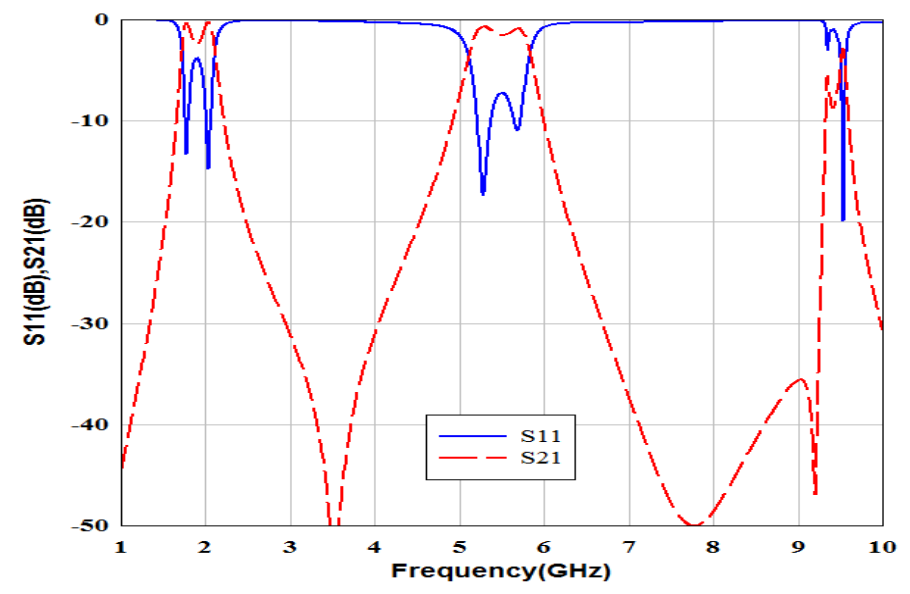

Figure 8. Return loss and insertion loss for modification filter

Table 2. Summary of Scaling Filter Frequency Performance Parameters from Figure 8

\begin{tabular}{|c|c|c|}
\hline Parameters & $1^{\text {st }}$ band & $2^{\text {nd }}$ band \\
\hline FBW\% & $14.5 \%$ & $9.17 \%$ \\
\hline $\mathrm{S}_{11}$ & $\begin{array}{l}-13.774 \mathrm{~dB} \text { at } 1.78 \mathrm{GHz} \\
-15.404 \mathrm{~dB} \text { at } 2.06 \mathrm{GHz}\end{array}$ & $\begin{array}{l}-11.226 \mathrm{~dB} \text { at } 5.2 \mathrm{GHz} \\
-14.112 \mathrm{~dB} \text { at } 5.7 \mathrm{GHz}\end{array}$ \\
\hline Center Frequency & $1.92 \mathrm{GHz}$ & $5.45 \mathrm{GHz}$ \\
\hline Minimum IL & $\begin{array}{l}-0.166 \mathrm{~dB} \text { at } 1.78 \mathrm{GHz} \\
-0.507 \mathrm{~dB} \text { at } 2.06 \mathrm{GHz}\end{array}$ & $\begin{array}{l}-0.930 \mathrm{~dB} \text { at } 5.2 \mathrm{GHz} \\
-0.533 \mathrm{~dB} \text { at } 5.7 \mathrm{GHz}\end{array}$ \\
\hline Transmission Zeros & $-90.02 \mathrm{~dB}$ at $0.1 \mathrm{GHz}$ & $\begin{array}{l}-57.379 \mathrm{~dB} \text { at } 3.52 \mathrm{GHz} \\
-45.153 \mathrm{~dB} \text { at } 9.206 \mathrm{GHz}\end{array}$ \\
\hline
\end{tabular}


The variation the shorting pin radius has been depicted in Figure 9. It can be seen that this parameter has a severe effect on the resonance frequencies of the degenerated bands and on the performance of the insertion loss with its transmission zeros of the resulting filter. The lower edge frequency of the lower band of the proposed BPF filter is tuned by the radius of the shorting pin as depicted in Figure 9a. The lowest insertion loss and higher out-of-band rejection levels are influenced by changing the shorting pin radius and about $-55 \mathrm{~dB}$ out-of-band rejections can be obtained as illustrated in Figure 9b.

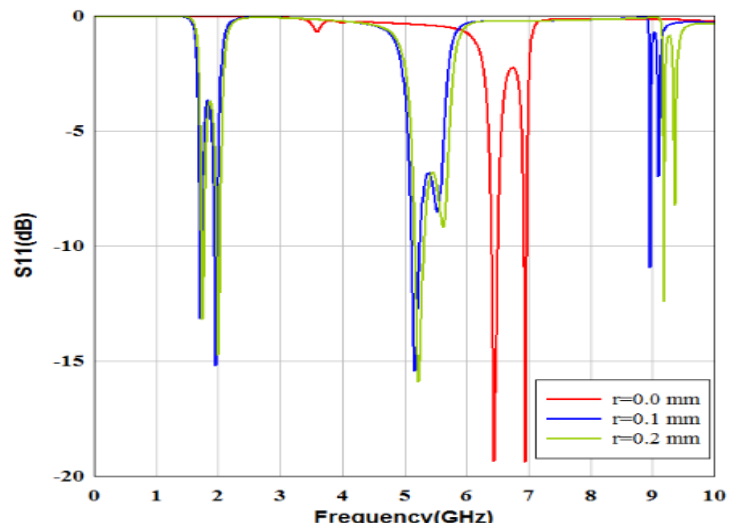

(a)

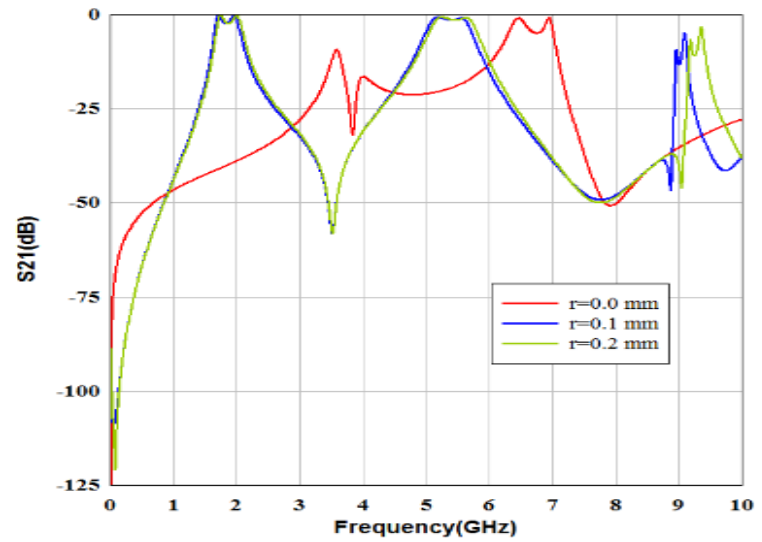

(b)

Figure 9. Effects of the variation shorting pin radius on (a) return (b) insertion loss of the resulting filter

\section{CONCLUSION}

A new dual mode Microstrip stepped impedance resonator band pass filter is proposed in this paper. The response of filter at $-3 \mathrm{~dB}$ fractional bandwidths of $14.5 \%$ and $9.17 \%$ respectively of the center frequencies $1.92 \mathrm{GHz}$ and $5.95 \mathrm{GHz}$ with an appropriate return and insertion losses for better responses, which covers the desired bands for wireless applications. The features of proposed filter are simple structure, consolidated size and good selectivity. Therefore, the filter is simple in structure and compact in size, which shows a new coupling structure. The filter has a good pass-band performance and improves the selectivity.

\section{REFERENCES}

[1] I. Husna, "Band-pass filter with harmonics suppression capability," TELEKOMNIKA (Telecommunication, Computing, Electronics and Control), Vol. 8, pp. 2512-2520, 2018.

[2] Z. Ali, Z. M. Hejazi, "Reconfigurable multiband bandpass filters using short bridges resembling MEMS or pin diodes," 2014 IEEE Student Conference on Research and Development, 2014.

[3] Y. Gaurav, "A Compact UWB BPF with a notch Band using Rectangular Resonator Sandwiched between Interdigital Structure," TELEKOMNIKA (Telecommunication, Computing, Electronics and Control), Vol. 7, pp. 2420-2425, 2017.

[4] Z. Aripin, Kusnandar, A. Najmurrokhman, and A. Munir, "Compact SRR-based microstrip BPF for wireless communication," 2015 2nd International Conference on Information Technology, Computer, and Electrical Engineering (ICITACEE), 2015.

[5] C.-X. Sun, L.-Y. Feng, X.-Y. Liu, H.-X. Zheng, "Compact Dual-Mode Filter Using Meander Shorted Stub Loaded Resonators," Progress in Electromagnetics Research Letters, Vol. 30, 195-203, 2012.

[6] Y. S. Mezaal, H. T. Eyyuboglu, J. K. Ali, "New Dual Band Dual-Mode Microstrip Patch Bandpass Filter Designs Based on Sierpinski Fractal Geometry," 2013 Third International Conference on Advanced Computing and Communication Technologies (ACCT), 2013.

[7] P. Vryonides, S. Nikolaou and S. Kim," Reconfigurable dual-mode band-pass filter with switchable bandwidth using PIN diodes," International Journal of Microwave and Wireless Technologies, Vol 7, Issue 6, December 2015.

[8] Y. S. Mezaal, J. K. Ali, "Investigation of Dual-Mode Microstrip Bandpass Filter Based on SIR Technique," Plos One, vol. 11, no. 10, 2016.

[9] Z.-T. Xu and J. Xu, "Design of dual-mode filters using stepped impedance resonators with stub loading," 2012 International Conference on Microwave and Millimeter Wave Technology (ICMMT), 2012.

[10] X. Huang, Q. Feng, Q. Y. Xiang, and D. Jia, "A High Selectivity Dual-Band Bandpass Filter Using Dual-Mode and Triple-Mode Resonators," Progress in Electromagnetics Research C, Vol. 36, 81-90, 2013.

[11] H. S. Lu, W. W. Wu, J. J. Huang, X. F. Zhang, and N. C. Yuan, "Compact Dual-mode Microstrip Bandpass Filter Based on Greek-cross Fractal Resonator,” Radioengineering, vol. 26, no. 1, pp. 275-284, 2017. 
[12] M. Makimoto and S. Yamashita, "Microwave Resonators and Filters for Wireless Communication," Berlin, Heidelberg: Springer-verlag, 2001.

[13] S. Meesomklin, P. Chomtong, P. Akkaraekthalin, "A Compact Multiband BPF Using Step-impedance Resonators with Interdigital Capacitors," Radioengineering, vol. 25, no. 2, pp. 258-267, 2016.

[14] J. Wang, L. Ge, K. Wang, W. Wu, "Compact microstrip dual-mode dual-band bandpass filter with wide stopband," Electronics Letters, vol. 47, no. 4, p. 263, 2011.

[15] H. Zhu, A. M. Abbosh, "Single and Dual-Band Bandpass Filters Using Coupled Stepped-Impedance Resonators with Embedded Coupled-Lines," IEEE Microwave and Wireless Components Letters, vol. 26, no. 9, pp. 675-677, 2016.

[16] Adnan Görür and Ceyhun Karpuz," Miniature Dual-Mode Microstrip Filters, " IEEE Microwave and Wireless Components Letters, Vol. 17, No. 1, January 2007.

[17] P. Wen, Z. Ma, H. Liu, S. Zhu, M. Ohira, C. Wang, X. Guan, B. Ren, "Novel Compact Dual-Band BPF Using Stub-Loaded Shorted Stepped-Impedance Resonators," 2018 Asia-Pacific Microwave Conference (APMC), 2018.

[18] M. Mokhtaari, J. Bornemann, and S. Amari, "Folded Compact Ultra-Wideband Stepped-Impedance Resonator Filters," 2007 IEEE/MTT-S International Microwave Symposium, 2007.

[19] L. Guo, Z.-Y. Yu, L. Zhang," Design of A Dual-Mode Dual-Band Filter Using Stepped Impedance Resonators," Progress in Electromagnetics Research Letters, Vol. 14, 147-154, 2010.

[20] Q.H. Zhang, Y.L. Dong, J.-G. Cao, "Dual-mode bandpass filter using microstrip SIR at Ka band," 2009 Asia Pacific Microwave Conference, 2009.

[21] J. Kuo, T. Yeh, C. Yeh, "Design of microstrip bandpass filters with a dual-passband response," IEEE Transactions on Microwave Theory and Techniques, Vol. 53, No. 4, Apr. 2005.

[22] P. Chomtong, P. Akkaraekthalin, "A quad-band bandpass filter using stepped impedance resonators with interdigital capacitors," IEEJ Transactions on Electrical and Electronic Engineering, vol. 13, no. 8, pp. 1080-1086, Feb. 2018.

[23] K. Kumar, N. Chaitanya, P. Kumar, B. Madhav, V. Ramesh and B. Nayak, "Comparative Analysis of Shorting Pin and Shorting Plate Models for Size Reduction in the Microstrip Patch Antennas", International Journal of Communication Engineering Applications-IJCEA, Vol. 2, July 2011.

[24] Ai Man. Lai, Hau Wah, "Microstrip Patch Antennas," $2^{\text {nd }}$ Edition, World Scientific Publishing, pp.343-380, 2017.

[25] J. Hong, "Microstrip Filters for RF/Microwave Application", 2nd Ed., John Wiley \& Sons, 2011. 